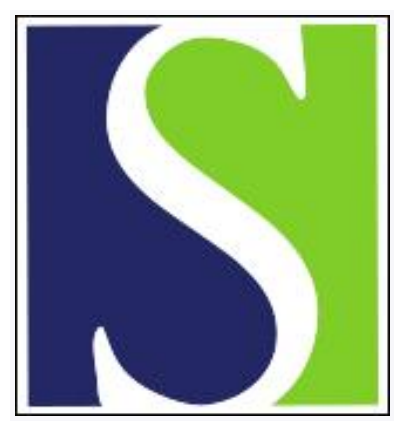

Scand J Work Environ Health 2007;33(4):286-292

https://doi.org/10.5271/sjweh.1145

Issue date: 31 Aug 2007

Incidence trends and gender differences in malignant mesothelioma in New South Wales, Australia

by Hyland RA, Ware S, Johnson AR, Yates DH

Affiliation: Workers' Compensation (Dust Diseases) Board, Level 14/82 Elizabeth St, Sydney 2000, New South Wales, Australia.

The following article refers to this text: 2019;45(1):82-89

Key terms: asbestos; Australia; gender difference; incidence trend; lung malignancy; malignant mesothelioma; woman

This article in PubMed: www.ncbi.nlm.nih.gov/pubmed/17717621

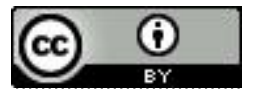




\title{
Incidence trends and gender differences in malignant mesothelioma in New South Wales, Australia
}

\author{
by Rebecca A Hyland, MIPH, ${ }^{1}$ Sandra Ware, MSc(Med), ${ }^{1}$ Anthony R Johnson MOHS, ${ }^{1}$ \\ Deborah $H$ Yates, $M D^{1,2}$
}

\begin{abstract}
Hyland RA, Ware S, Johnson AR, Yates DH. Incidence trends and gender differences in malignant mesothelioma in New South Wales, Australia. Scand J Work Environ Health 2007;33(4):286-292.
\end{abstract}

\begin{abstract}
Objectives Features of malignant mesothelioma reportedly differ between men and women, including occupational asbestos exposure, histological subtype, and median survival. In this study, incidence trends and clinical features for malignant mesothelioma were compared between genders in New South Wales (NSW), where notification of malignant mesothelioma to the Central Cancer Registry is a statutory requirement.

Methods Notifications to the Central Cancer Registry were compared with those to the registry of the NSW Workers' Compensation (Dust Diseases) Board. The latter includes occupational and clinical data.

Results Of the 3090 cases of malignant mesothelioma reported to the Central Cancer Registry between 1972 and 2004, 456 (15\%) were female. Altogether 1995 malignant mesotheliomas were compensated between 1969 and 2004, of which 105 (5\%) occurred among women. The incidence increased for both genders by approximately 15-fold. Median survival was similar for the men and women for all of the cases ( 7 versus 6 months), but was better among the women who received compensation ( 8.5 versus 10.4 months, $\mathrm{P}<0.0001)$. The mean disease latency (42.8 years) increased over the study period $(\mathrm{P}<0.001)$.

Conclusions In New South Wales over the last 30 years, the total number of malignant mesotheliomas and the number of compensated cases of malignant mesothelioma have risen for both genders. The mean latency is increasing, and increasing numbers of "nonoccupational" cases are being reported. Survival remains poor.
\end{abstract}

Key terms asbestos; lung malignancy; women.

Malignant mesothelioma is a rare tumor causally related to asbestos exposure. Several studies have shown an increasing incidence of this disease, which has probably already peaked in the United States, and is predicted to peak in Europe between 2010 and 2020 (1, 2). Australia had heavy asbestos usage in the 1950s and 1960s, and one report has predicted a total of 18000 malignant mesothelioma cases by $2020(3,4)$.

The current malignant mesothelioma epidemic has principally affected men. However, increasing numbers of women with malignant mesothelioma are also being diagnosed. Information about women is of particular interest because clinical differences have been reported between men and women and differing susceptibility towards malignant mesothelioma is also suspected. Associations with asbestos differ between pleural and peritoneal malignant mesothelioma, and this difference is likely to be relevant with respect to gender differences. In addition, malignant mesothelioma in women is more likely to reflect background (or nonoccupational) asbestos exposure and thus elucidate the relationship between low levels of asbestos exposure and disease.

Malignant mesothelioma is relatively uncommon in women; cases of malignant mesothelioma among women have been reported in reviews and other papers as ranging between $13 \%$ and $23 \%$ of the cases $(5,6)$. Household contact with an asbestos worker is a welldocumented source of asbestos exposure among women (7-11), but women may also be exposed from environmental or occupational contact. Usually, less than $10 \%$ of an asbestos-exposed workforce is female (12). In Australia, cases among women have been reported to account for approximately $19 \%$ of the total cases (13). Due to relatively small numbers and difficulties in obtaining accurate data, few previous studies have assessed gender differences, and most do not distinguish between genders or have sufficient occupational data to comment on asbestos exposure (14-18).

1 Workers' Compensation (Dust Diseases) Board Education \& Research Unit, Sydney, New South Wales, Australia.

2 Department of Thoracic Medicine, St Vincent's Hospital, Darlinghurst, Sydney, New South Wales, Australia.

Reprint requests to: Dr Deborah H Yates, Research and Education Unit, Workers' Compensation (Dust Diseases) Board, Level 14/82 Elizabeth St, Sydney 2000, New South Wales, Australia. [E-mail: Deborahy88@ hotmail.com] 
In order to study malignant mesothelioma in New South Wales (NSW), including trends in incidence and occupational and clinical differences between genders, we collated cases from the NSW Central Cancer Registry and the NSW Workers' Compensation (Dust Diseases) Board registry, representing total and compensated cases, respectively. The registry of the Dust Diseases Board includes detailed clinical and occupational information, but the Central Cancer Registry does not. We aimed to compare gender incidence trends, including "nonoccupational" cases, and to assess whether clinical features (including survival, latency from exposure, and histological type) differ between men and women. Our data relate primarily to pleural malignant mesothelioma because we had few peritoneal cases. There is ample evidence that associations with asbestos differ between peritoneal and pleural malignant mesothelioma.

\section{Material and methods}

In this study, we prospectively collected clinical, pathological, and occupational information on all persons with malignant mesotheliomas from the two registries applying to New South Wales between 2000 and 2004. The study was approved by the local human research ethics committee (HREC) and the human research ethics committee of the NSW Cancer Institute, and only deidentified data were used. We also collected information from past recorded cases of malignant mesothelioma from both registries when available.

The NSW Central Cancer Registry maintains a register of all cases of cancer diagnosed in New South Wales from 1972 to the present day. Notification of cancer is a statutory requirement for all public and private hospitals, radiotherapy departments, nursing homes, pathology departments, and outpatient departments (19). Thus, should one of these institutions diagnose or treat somebody with cancer, they are required by law to notify the Central Cancer Registry. Consequently multiple notifications are often received for a given case. Site, histopathology, cytopathology, location of tumor, as well as the age and gender of the person involved, are recorded, but no occupational data or clinical information is available. Cases are only recorded if the cancer is diagnosed in New South Wales.

The NSW Dust Diseases Board is a statutory authority that provides compensation to workers with dust diseases attributable to dust exposure while employed in New South Wales. Compensation is awarded for pathologically proven malignant mesothelioma if the applicant has been occupationally exposed to asbestos in New South Wales. Nonoccupationally exposed, selfemployed, and Commonwealth employees are excluded. Cases of domestic exposure (eg, a wife washing her husband's clothes) are also excluded, as the applicant must have been formally employed when the asbestos exposure occurred. An award is made after the diagnosis has been established by the Medical Authority of the Dust Diseases Board, a panel of three respiratory physicians specializing in occupational lung disease. Detailed clinical and pathological information is available to the Medical Authority and is evaluated along with the occupational history and radiology. In cases of malignant mesothelioma, tissue is available in $98 \%$ of the cases and is subject to expert pathological review. For histopathology sections, a variety of histochemical and immunohistochemical stains is used, Periodic Acid Schiff (PAS) diastase, mucicarmine, and Alcian blue and carcinoembyronic antigen (CEA), cytokeratin, vimentin, and calretinin, among others, where required. In the minority of cases in which cytology only is available, electron microscopy is used if cytological stains are nondiagnostic. Malignant mesothelioma is diagnosed when the applicant has had documented asbestos exposure during his or her worklife with a compatible latency period, and there is also sufficient clinical evidence to diagnose malignant mesothelioma rather than any other malignancy on the balance of probabilities. Lifetime occupational histories are also required and are taken into account when compensation is decided upon. They are collected in face-to-face interviews between clients and advisory officers of the Dust Diseases Board. In a minority of cases, when the applicant is deceased, these interviews take place with the next of kin. For malignant mesothelioma, a history of asbestos exposure in New South Wales is all that is required, and no exposure criteria are otherwise used. Exposures to different types of asbestos are not taken into account, as most exposures in New South Wales involve several types of asbestos and most applicants have had exposure in more than one workplace. The method of awarding compensation for malignant mesotheliomas has not changed since 1969 , although several developments in histochemical staining have been incorporated over the years, as have new medical imaging techniques (eg, computerized tomographic scanning).

For this study, paperwork was retrieved for all of the cases, and data were entered into a standardized database so that potential coding changes were negated. Occupation, industry, and task were all coded, but were not recorded in earlier cases. However, after all of the original paper records were retrieved (including occupational histories, although these were less detailed in earlier years), they could be entered appropriately. Information on all malignant mesotheliomas compensated by the NSW Dust Diseases Board was collected from the earliest recorded awards (1969) to 2004.

For the cases from the Dust Diseases Board, the following information was recorded: gender, date of birth, 
date diagnosed, date of death, method of diagnosis, location of tumor, histopathology, location of the malignant mesothelioma, and occupational information, including period of employment, employer name, employer industry, and job title. For this study, the histopathology of the women with peritoneal malignant mesothelioma was reconfirmed by at least two pathologists (20). In order to approximately assess possible nonoccupationally exposed cases, the annual difference between the cases from the NSW Cancer Council (or total) and those of the Dust Diseases Board was calculated when information was available for each year from each registry (data not shown but available on request).

\section{Statistics}

A statistical analysis was performed using statistical software SPSS 13.0 for windows (SPSS Inc, Chicago, IL, USA). Kaplan Meier plots were performed to analyze the age effects and survival (21). A chi-square test was used for the analysis of categorical variables (22), and continuous variables were compared using two-tailed t-tests (23). Cox's regression was used to examine the relationship between the effect of gender on survival, disease type, and survival by gender, and year of diagnosis and survival. A P-value of less than 0.05 was considered significant.

\section{Results}

\section{Incident cases and comparison between registries}

Annual numbers of incident cases of malignant mesothelioma among men recorded by the Central Cancer
Registry and the Dust Diseases Board were compared with the incident figures of women, and are shown in figure 1. The Central Cancer Registry recorded 3090 cases between 1972 and 2004. Of these, 456 (15\%) were among women and 2634 were among men. Altogether $15 \%$ and $6 \%$ of the cases among the women and men, respectively, were peritoneal. Altogether 1995 malignant mesotheliomas (5\% among women) were compensated by the Dust Diseases Board over a 35-year period. Of these, 1884 (94\%) were pleural (5\% among women), and 111 were peritoneal ( $5 \%$ among women). The peritoneal cases represented $6 \%$ of both the men and the women.

The Dust Diseases Board compensated approximately $60 \%$ of all the malignant mesothelioma cases notified to the Central Cancer Registry in that period. When the differences between the two registries were compared for each gender, a continued increase in incidence was observed for both the men and the women.

\section{Occupational exposures}

Occupational data were available for $100 \%$ of the women and $98 \%$ of the men for the registry of the Dust Diseases Board, but none from the registry of the Central Cancer Registry. The most common occupations when first asbestos exposure was reported are shown in table 1 . No single occupation was shared between the genders when the top five occupations of men and women were compared. The most common occupations for the women were steam press operator $(15 \%)$, process worker $(14 \%)$, and clerical worker (14\%). The most common industry reported for the women was textile manufacturing. In contrast to the men, most of the women worked in nonmanual labor and in indoor occupations. The most

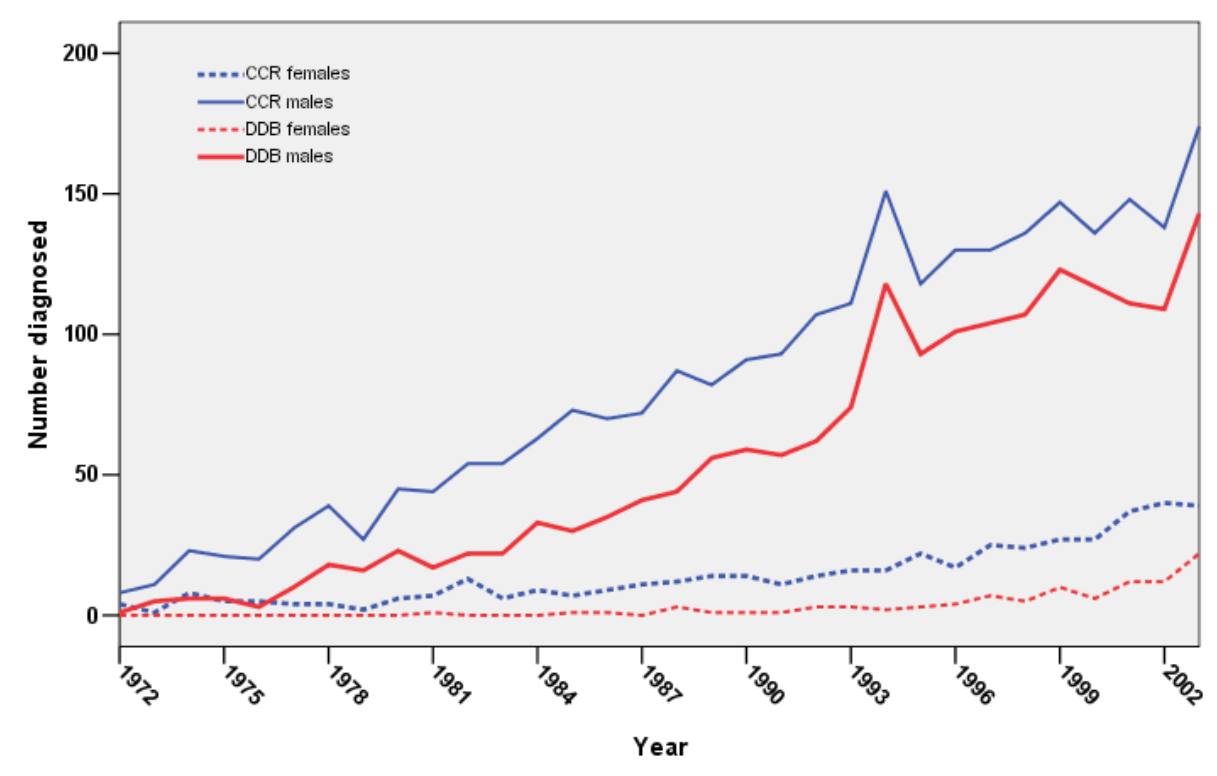

Figure 1. Comparison of incident malignant mesothelioma cases recorded by the Central Cancer Registry (CCR) and by the Workers' Compensation (Dust Diseases) Board (DDB) between 1964 and 2004. 
common occupation for the men was carpenter followed by fitter and trade assistant.

\section{Latency}

Latency period was defined as the time (in years) between the year of first exposure to asbestos and the year of diagnosis. Overall, there was no significant difference in latency between the men and women (43.7 versus 42.8 years, respectively, $\mathrm{P}=0.439)$. However, the latency was significantly shorter for peritoneal malignant mesothelioma among both the men (38.8 versus 44 years, $\mathrm{P}<0.01)$ and the women $(29.7$ versus 43.6 years, $\mathrm{P}<0.01$ ) compared with their pleural counterparts. Linear regression modeling showed that latency was increasing for both pleural and peritoneal forms of the disease $\left(\mathrm{R}^{2}=0.111, \mathrm{P}<0.0001\right)$.

\section{Clinical features}

A comparison of clinical features between the genders derived from the registry of the Dust Diseases Board is shown in table 2. Insufficient data were available from the Central Cancer Registry for a similar analysis. No difference was found between the median age of diagnosis between the men and women with pleural malignant mesothelioma (70 versus 67.7 years, respectively, $\mathrm{P}=\mathrm{NS})$. Although peritoneal cases were presented at a younger age (58.7 versus 64.1 years, $\mathrm{P}=\mathrm{NS}$ ) among the women, this age difference was not statistically significant.

Information on histological classification and the site of the pleural tumor was available for $90 \%$ of the cases from the Dust Diseases Board (table 2). Epithelial histology was the most common subtype $33.8 \%$ of the pleural cases among the men versus $49.5 \%$ of the cases among the women). For both genders, sarcomatous cell type was associated with the poorest survival (men: RR 1.94, $\mathrm{P}<0.0001$; women: RR 1.92, $\mathrm{P}<0.0001)$. Compatible with other reports, right-sided malignant mesotheliomas were more common than left-sided ones.

\section{Survival}

Survival was poor among both genders (figure 2). Overall, the women survived significantly longer than the

Table 1. Most common occupations in which exposure to asbestos had occurred for the compensated mesothelioma cases $(\mathrm{N}=1961)$ among the men and women from the Workers' Compensation (Dust Diseases) Board registry.

\begin{tabular}{lr}
\hline Gender & $\%$ \\
\hline Males (N=1856) & \\
Carpenter & 19.9 \\
Fitter & 15.7 \\
Trades assistant & 9.3 \\
Electrician & 9.0 \\
Asbestos workers & 8.8 \\
Boilermaker & 6.5 \\
Process worker & 6.2 \\
Builders worker & 5.6 \\
Plumber & 4.1 \\
Store person & 3.5 \\
Females (N=105) & \\
Steam press operator & 15.1 \\
Process worker & 14.3 \\
Clerical worker & 14.3 \\
Textile machine operator & 11.8 \\
Cleaner & 7.6 \\
Sales person & 6.7 \\
Laundry worker & 5.9 \\
Teacher & 5.0 \\
Store person & 4.2 \\
Nurse & 3.4 \\
\hline
\end{tabular}

Table 2. Characteristics of the compensated malignant mesothelioma cases ( $\mathrm{N}=1995)$ from the Workers' Compensation (Dust Diseases) Board registry.

\begin{tabular}{|c|c|c|c|c|c|c|c|c|c|c|c|c|c|}
\hline \multirow[t]{2}{*}{$\begin{array}{l}\text { Meso- } \\
\text { theliomas }\end{array}$} & \multicolumn{2}{|r|}{ Age at diagnosis } & \multicolumn{4}{|c|}{ Survival } & \multicolumn{2}{|c|}{ Latency } & \multicolumn{2}{|r|}{ Histology } & \multicolumn{2}{|r|}{$\begin{array}{l}\text { Diagnostic } \\
\text { method (\%) }\end{array}$} & $\begin{array}{l}\text { Laterality } \\
(\%)\end{array}$ \\
\hline & N & $\begin{array}{l}\text { Median Range } \\
\text { (years) (years) }\end{array}$ & $\mathrm{N}$ & $\begin{array}{l}\text { De- } \\
\text { ceased } \\
(\%)\end{array}$ & $\begin{array}{c}\text { Me- } \\
\text { dian } \\
\text { (months) }\end{array}$ & $\begin{array}{l}\text { Range } \\
\text { (months) }\end{array}$ & $\mathrm{N}$ & $\begin{array}{l}\text { Mean } \\
\text { (years) }\end{array}$ & $\begin{array}{l}\text { Sarco- } \\
\text { ma- } \\
\text { tous }\end{array}$ & $\begin{array}{l}\text { Mixed Not } \\
\text { known }\end{array}$ & $\begin{array}{l}\text { Histo- } \\
\text { logy }\end{array}$ & $\begin{array}{l}\text { Cyto- Cli- Not } \\
\text { logy nical known }\end{array}$ & Right Left $\underset{\text { known }}{\text { Not }}$ \\
\hline
\end{tabular}

All

\begin{tabular}{|c|c|c|c|c|c|c|c|c|c|c|c|c|c|c|c|c|c|c|c|}
\hline Men & 1890 & 67.5 & 24-93 & 1771 & 94 & 8.5 & 0-220 & 1837 & 43.7 & 14.4 & 13.9 & 38 & 90 & 7.2 & 0.7 & 2.1 & 50.4 & 50.3 & 14.2 \\
\hline Women & 105 & 68.8 & 39-90 & 87 & 83 & 10.4 & $0.8-145$ & 104 & 42.8 & 9.5 & 9.5 & 31.4 & 89.5 & 7.6 & 2.9 & a & 44.8 & 40 & 15.2 \\
\hline \multicolumn{20}{|l|}{ Pleural } \\
\hline Men & 1785 & $67.7^{\mathrm{b}}$ & $24-93$ & 1678 & 94 & 8.6 & 0-186 & 1736 & $44^{b}$ & 15 & 14.3 & 36.9 & 89.9 & 7.2 & 0.8 & 2.2 & 53.3 & 37.3 & 4 \\
\hline Women & 99 & $70^{b}$ & $43-90$ & 86 & 87 & $9.3^{c}$ & $0.8-145$ & 98 & $43.6^{b}$ & 10.1 & 10.1 & 32.3 & 88.9 & 8.1 & 3 & a & 47.5 & 41.4 & 1 \\
\hline \multicolumn{20}{|c|}{ Peritoneal } \\
\hline Men & 105 & 64.1 & $33-89$ & 93 & 88 & 5.6 & $0-220$ & 102 & 38.8 & 3.8 & 7.5 & 56.6 & 92.5 & 7.5 & a & a & a & a & a \\
\hline Women & 6 & 58.7 & $39-67$ & 1 & 17 & 43.9 & $1-51$ & 6 & 29.7 & a & a & 16.7 & 100 & a & a & a & a & a & \\
\hline
\end{tabular}

a Numbers too small for analysis.

${ }^{b} \mathrm{P}<0.01$.

c $P<0.05$. 


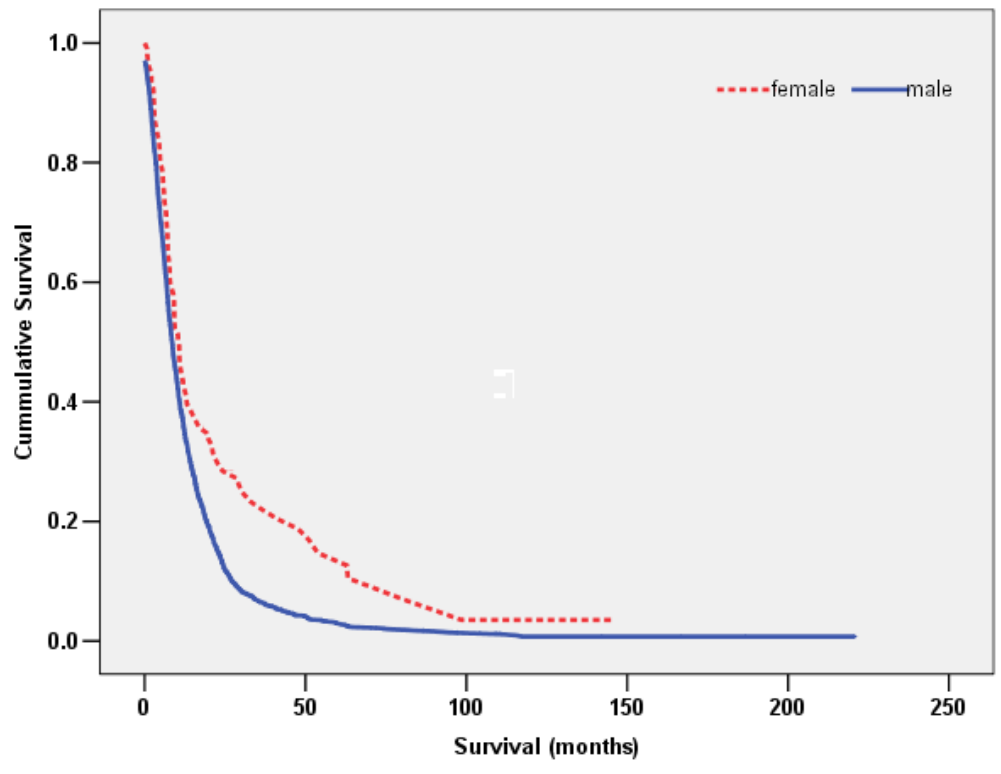

Figure 2. Cumulative survival for both the men and women with malignant mesothelioma from the Workers' Compensation (Dust Diseases) Board registry. men (median survival 10.4 months for the women versus 8.5 months for the men, $\left.X^{2}=17.74, \mathrm{P}<0.0001\right)$. There was no significant difference in the length of survival between the men with pleural and peritoneal malignant mesothelioma (8.6 versus 5.6 months, $\mathrm{P}=$ not significant). However for the women, survival was significantly longer for the peritoneal cases $(9.3$ versus $43.9, \mathrm{P}<0.05)$, although the numbers were so small as to be unreliable $(\mathrm{N}=6)$. A significant change in the mean survival occurred over time $\left(X^{2}=20.08, \mathrm{P}<0.0001\right)$. For both genders, there was a significant association between age at diagnosis and survival (men: $X^{2}=28.49, \mathrm{P}<0.0001$; women: $\left.X^{2}=7.25, \mathrm{P}=0.007\right)$. Similarly, the year of diagnosis was significantly related to survival $(\mathrm{P}<0.0001)$. The greater proportion of the epithelial subtype among the women did not account for their improved survival.

\section{Discussion}

Our study confirms previous reports suggesting that the malignant mesothelioma epidemic has not yet peaked in Australia (4). It provides detailed information on occupational exposures between the genders in New South Wales for the first time and confirms the better survival of compensated women with malignant mesothelioma. The total numbers of malignant mesothelioma are increasing among both genders.

In New South Wales, the annual number of cases of malignant mesothelioma has now reached 213, the age-standardized incidence rate being 5.2 for men per 100000 of the population compared with 1.2 per 100000 for women (24). This rate compares with 1874 cases annually (men 5.6 versus women 0.9 per 100000 ) in the United Kingdom (3) and 2728 annually in the United States (men 1.7 versus women 0.4 per 100 000) (25). Thus our incident rates for women are a little higher but comparable with those of other industrialized countries, lending validity to our findings, although higher than in the United States, where malignant mesothelioma rates are now declining.

Our study found that malignant mesotheliomas among men still outnumber malignant mesotheliomas among women, in a ratio of approximately $5: 1$. To date, almost all of the studies from the industrialized countries have shown that malignant mesothelioma is much more common among men than among women (26-29) with a proportion of approximately 5:1 for men: women, confirming its occupational etiology. However, studies from Turkey examining the risk of development of malignant mesothelioma from environmental exposure to asbestos-contaminated soil mixtures have, on the contrary, found a female gender predilection (30), with a male:female ratio of $1: 1.4$. While it is possible that this difference may relate solely to exposure in the home, genetic factors may also be relevant. In New South Wales, our male:female ratio suggests that occupational factors still hugely outweigh other potential causes, although possible "nonoccupational" cases appear also to be increasing. Asbestos was widely used in Australia in the 1950s-1960s for construction of "fibro" housing, particularly in kitchens and bathrooms. Home renovations can release respirable asbestos fibers, albeit at low levels. Thus it will be particularly interesting to compare incidence rates between genders in Australia in comparison with those of other countries in the future.

In our study, for which detailed information was available from the register of the Dust Diseases Board, 
latency from first occupational exposure to diagnosis increased, both for pleural and peritoneal disease, and among both genders. This increase is in keeping with other reports $(18,27,31)$. The most widely quoted review on latency data, published over 10 years ago, looked at data from 21 studies and estimated the median latency to be 32 years (32), but recent studies report a much longer latency of about 40 years $(14,15$, 33 ) and even longer in one study (59.2 years for both men and women) (30). This increase in latency may reflect decreasing levels of asbestos exposure $(18,31)$ or improved survival from other causes, suggesting that, with increasing life expectancy in the developed world, a greater incidence of malignant mesothelioma in the older population might be expected (34).

We found that women compensated for malignant mesothelioma survived longer, despite an identical age of diagnosis. Clinical features were otherwise identical between the genders. Although epithelial subtype was more common among women, this situation did not account for the increased survival of the women. This finding is compatible with the results of several other studies, which, in addition to better survival for women, have also found that women have a greater propensity to develop peritoneal malignant mesothelioma $(35,36)$. Women are also thought to have a higher background incidence of malignant mesothelioma (34), but it is unclear whether this is a result of physiological differences, perhaps producing differences in carcinogen deposition. These gender differences are similar to those reported for lung cancer (37). The reasons for the better survival of women compensated for malignant mesothelioma in our study are speculative. Our data negate the possibility of earlier diagnosis (except possibly for peritoneal malignant mesothelioma), and, in any case, there are data to suggest that diseases are generally diagnosed earlier for men. Hormonal factors seem unlikely, given the postmenopausal presentation of malignant mesothelioma in our study. Given the bias inherent in a compensation registry, it is still possible that this finding is a type II error.

The limitations of our study should be kept in mind when our data are interpreted. Data from the registry of the Dust Diseases Board originates from a group compensated for malignant mesothelioma and thus has significant selection bias. The register of the Dust Diseases Board does not include nonoccupationally exposed, self-employed, or Commonwealth employees and is, therefore, a subgroup of those exposed to asbestos. Thus women with domestic exposure who have washed their husband's clothes, for example, are not compensated. Our study had no way of detecting such cases. For the cases in the Central Cancer Registry, notifications are likely to underrepresent the total number of malignant mesotheliomas in New South Wales, although the underestimate is likely to be small. In addition, the Central Cancer Registry only records malignant mesotheliomas diagnosed within the state, and, given the long latency for the development of this disease, it is likely that some patients with malignant mesothelioma reside outside New South Wales. Calculating differences between the registers of the Central Cancer Registry and Dust Diseases Board provides only a crude estimate of "nonoccupational" cases, although biases are likely to have remained stable over the reporting period.

Changes in reporting, collecting, or coding exposure information could easily have affected our results, and there is no way of ensuring that such changes did not take place in our study. We retrieved all of the paper files and recoded all of the records to ensure that such differences did not play a role, but it is likely that changes in awareness regarding the health hazards of asbestos exposure did occur over this period, and these would have significantly affected our results. Similarly, changes in diagnostic methods, as well as the awareness of malignant mesothelioma, could affect the award of compensation by the Medical Authority. However, such changes would affect the genders equally. Gender differences in occupational exposure could also be attributed (partly or wholly) to recollection bias, as occupational histories taken some 40 years after the relevant exposure are inherently unreliable. Sources of asbestos exposure may be more difficult to identify among women than among men (4), and it is possible that doctors do not as readily identify malignant mesothelioma in female patients.

Over the last few years, research into malignant mesothelioma has yielded promising results, and several new treatments are now available. Newer therapies are under development, and suitably designed prospective trials are currently underway to evaluate treatments. It is possible that the early detection of malignant mesothelioma will allow earlier treatment and improve overall prognosis. Our study confirms that, in New South Wales, malignant mesothelioma is an increasingly common diagnosis among both genders. Understanding the clinical factors important for survival with respect to this malignancy could potentially elucidate factors that could be targeted for treatment for malignant mesothelioma, and knowledge regarding differences in gender incidence with respect to malignant mesothelioma may lead to a better understanding of the relevance of low levels of asbestos to the development of this disease.

\section{Acknowledgments}

This study was funded by a grant from the Workers' Compensation (Dust Diseases) Board of New South Wales. 
We would like to thank Nari Clarke and Maxine Tan for their database entries and the Cancer Council of New South Wales for their cooperation.

\section{References}

1. Peto, J, Hodgson J, Matthews F, Jones J. Continuing increase in mesothelioma mortality in Britain. Lancet. 1995;345(8949):535-9.

2. Weill H, Hughes JM, Churg A. Changing trends in US mesothelioma incidence. Occup Environ Med. 2004;61:438-41.

3. Health \& Safety Executive. HSE—-statistics: mesothelioma. Health \& Safety Executive; 2003 [cited: 6 June 2007]. Available from: http://www.hse.gov.uk/statistics/causdis/meso. htm).

4. Leigh J, Davidson P, Hendrie L, Berry D. Malignant mesothelioma in Australia. Am J Ind Med. 2002;41:188-201.

5. Hillerdal G. Malignant mesothelioma 1982: review of 4710 published cases. Br J Dis Chest. 1983;77(4):321-43.

6. Agudo A, Gonzalez CA, Bleda MJ, Ramirez J, Hernandez S, Lopez F, et al. Occupation and risk of malignant pleural mesothelioma: a case-control study in Spain. Am J Ind Med. 2000;37(2):159-68.

7. Vianna N J, Polan AK. Non-occupational exposure to asbestos and malignant mesothelioma in females. Lancet. 1978;1(8073):1061-3.

8. Roggli VL, Oury T, Moffatt EJ. Malignant mesothelioma in women. Anat Pathol 1997;2:147-63.

9. Epler GR, FitzGerald MX, Gaensler EA, Carrington CB. Asbestos-related disease from household exposure. Respiration. 1980;39(4):229-40.

10. Dodson RF, O’Sullivan R, Brooks DR, Hammar SP. Quantitative analysis of asbestos burden in women with mesothelioma. Am J Ind Med. 2003;43(2):188-95.

11. Case B, Camus M, Richardson L, Parent M, Desy M, Siemiatycki J. Preliminary findings for pleural mesothelioma among women in the Quebec chrysotile mining regions. Ann Occup Hyg. 2002;46, suppl 1:128-131.

12. Walker AM, Loughlin JE, Friedlander ER, Rothman KJ, Dreyer NA. Projections of asbestos-related disease 1980-2009. J Occup Med. 1983;25(5):409-25.

13. National Occupational Health and Safety Commission. The incidence of mesothelioma in Australia 1999-2001: Australian Mesothelioma Register Report 2004. Canberra: National Occupational Health and Safety Commission; 2004.

14. Yeung $P$, Rogers A. An occupation-industry matrix analysis of mesothelioma cases in Australia 1980-1985. Appl Occup Environ Hyg. 2001;16(1):40-4.

15. Burdorf A, Dahhan M, Swuste P. Occupational characteristics of cases with asbestos-related diseases in The Netherlands. Ann Occup Hyg. 2003;47(6):485-92.

16. Leigh J, Driscoll T. Malignant mesothelioma in Australia, 1945-2002. Int J Occup Environ Health. 2003;9:206-17.

17. Nesti M, Marinaccio A, Chellini E, Centres RO. Malignant mesothelioma in Italy, 1997. Am J Ind Med. 2004;45:55-62.

18. Bianchi C, Brollo A, Ramani L, Bianchi T, Giarelli L. Asbestos exposure in malignant mesothelioma of the pleura: a survey of 557 cases. Ind Health. 2001;39(2):161-7.

19. Public Health Act 1994. Public Health (Cancer Reporting) Regulations Subordinate Law no 19. [cited: 6 June 2007].
Available from: http://www.legislation.act.gov.au/sl/1994-19/ default.asp.

20. Krasuski P, Poniecka A, Gal E. The diagnostic challenge of peritoneal mesothelioma. Arch Gynecol Obstet. 2002;266(3):130-2.

21. Kaplan E, Meier P. Non parametric estimation from incomplete observations. J Am Stat Assoc. 1958;53:457-81.

22. Pearson K. On the criterion that a given system of deviations from the probable in the case of a correlated system of variables is such that it can be reasonably supposed to have arisen from random sampling. Philosophical Magazine. 1900;series 5(50);157-75.

23. Altman D. Practical statistics for medical research. Chapman \& Hall; 1994. p 455-60.

24. Tracey T, Roder D, Bishop J, Chen S, Chen C. Cancer in New South Wales: incidence and mortality 2003. New South Wales (Australia): New South Wales Central Cancer Registry, Cancer Institute of New South Wales [cited 31 July 2007]. Available from: http://www.health.nsw.gov.au/cancer_inst/publications/ pdfs/IncidenceMortalityReport2003.pdf.

25. Centers for Disease Control and Prevention (CDC). National Program of Cancer Registries, Incidence and Mortality Data 2001 [cited 6 June 2007]. Available from: http://apps.nccd.cdc. gov/uscs/index.asp?Year=2001).

26. Spirtas R, Heineman EF, Bernstein L, Beebe GW, Keehn RJ, Stark A, et al. Malignant mesothelioma: attributable risk of asbestos exposure. Occup Environ Med. 1994;51(12):804-11.

27. Yates DH, Corrin B, Stidolph PN, Browne K. Malignant mesothelioma in south east England: clinicopathological experience of 272 cases. Thorax. 1997;52(6):507-12.

28. Albin M, Magnani C, Krstev S, Rapiti E, Shefer I. Asbestos and cancer: an overview of current trends in Europe. Environ Health Perspect. 1999;107 suppl 2:289-98.

29. Ribak J, Lilis R, Suzuki Y, Penner L, Selikoff IJ. Malignant mesothelioma in a cohort of asbestos insulation workers: clinical presentation, diagnosis, and causes of death. Br J Ind Med. 1988;45(3):182-7.

30. Metintas S, Metintas M, Ucgun I, Oner U. Malignant mesothelioma due to environmental exposure to asbestos: follow-up of a Turkish cohort living in a rural area. Chest. 2002;122(6):2224-9.

31. Yeung P, Patience K, Apthorpe L, Willcocks D. An Australian study to evaluate worker exposure to chrysotile in the automotive service industry. Appl Occup Environ Hyg. 1999;14(7):448-57.

32. Lanphear BP, Buncher CR. Latent period for malignant mesothelioma of occupational origin. J Occup Med. 1992;34(7):718-21.

33. Neumann V, Gunthe S, Mulle K, Fischer M. Malignant meosthelioma-German mesothelioma register 1987-1999. Int Arch Occup Environ Health. 2001;74:383-95.

34. Smith DD. Women and mesothelioma. Chest. 2002; 122(6):1885-6.

35. Cocco P, Dosemeci M. Peritoneal cancer and occupational exposure to asbestos: results from the application of a jobexposure matrix. Am J Ind Med. 1999;35(1):9-14.

36. Dawson A, Gibbs AR, Pooley FD, Griffiths MD, Hoy J. Malignant mesothelioma in women. Thorax. 1993;48(3):269-74.

37. Fu JB, Kau TY, Severson RK, Kalemkerian GP. Lung cancer in women: analysis of the national Surveillance, Epidemiology, and End Results database. Chest. 2005;127(3):768-77.

Received for publication: 5 July 2006 